\title{
REVISED Intrinsic negative feedback as a limiting factor for the evolution of higher forms of intelligence [version 3; peer
}

\section{review: 2 approved]}

\author{
Stefan T. Arold (D) 1,2
}

${ }^{1}$ Division of Biological and Environmental Sciences and Engineering, King Abdullah University of Science and Technology, Thuwal, MK, 23955-6900, Saudi Arabia

${ }^{2}$ Centre de Biologie Structurale, CNRS, INSERM, Université de Montpellier, 34090 Montpellier, France

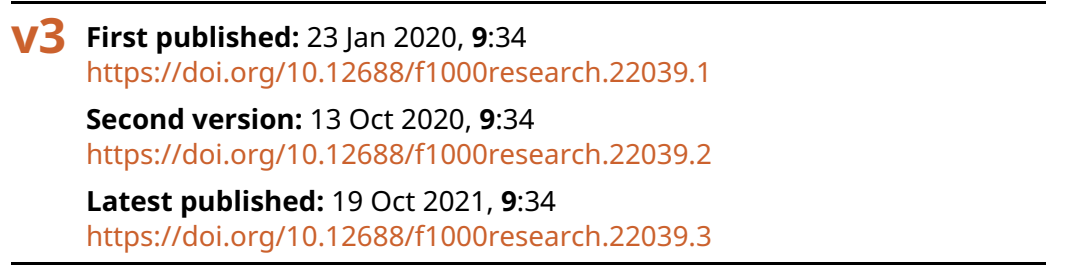

\begin{abstract}
Longstanding scientific efforts have been dedicated to answer why and how our particular intelligence is generated by our brain but not by the brain of other species. However, surprisingly little effort has been made to ask why no other species ever developed an intelligence similar to ours. Here, I explore this question based on genetic and paleontologic evidence. Contrary to the established view, this review suggests that the developmental hurdles alone are not high enough to explain the uniqueness of human intelligence (HI). As an additional explanation I propose that $\mathrm{HI}$ is normally not retained by natural selection, because it is, under most conditions, an intrinsically unfavourable trait. This unfavourableness, however, cannot be explained by physical constraints alone; rather, it may also be rooted in the same emotional and social complexity that is necessary for the development of HI. Thus, a major obstacle towards HI may not be solely the development of the required physical assets, but also to cope with harmful individual, social and environmental feedback intrinsically associated with this trait.

\section{Keywords} iterative evolution, convergent evolution, cognition, complexity, gene expression, sustainability
\end{abstract}

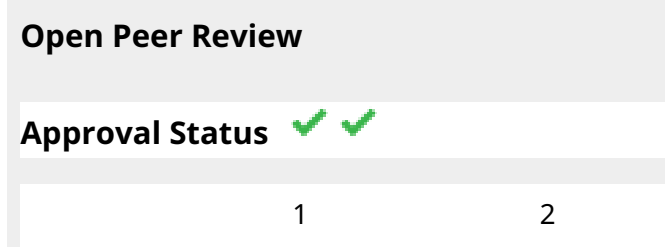

version 3

(revision)

19 Oct 2021

version 2

(revision)

13 Oct 2020

version 1

23 Jan 2020

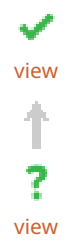

1. Rafael Bretas Vieira (ID), RIKEN Center for Biosystems Dynamics Research, Kobe, Japan Atsushi Iriki, RIKEN Center for Biosystems Dynamics Research, Kobe, Japan

2. Robert J Sternberg, Cornell University, Ithaca, USA

Any reports and responses or comments on the article can be found at the end of the article. 
Corresponding author: Stefan T. Arold (stefan.arold@kaust.edu.sa)

Author roles: Arold ST: Conceptualization, Data Curation, Formal Analysis, Funding Acquisition, Investigation, Methodology, Project Administration, Writing - Original Draft Preparation, Writing - Review \& Editing

Competing interests: No competing interests were disclosed.

Grant information: Research reported in this publication was supported by the King Abdullah University for Science and Technology (KAUST) through the baseline funding to STA (BAS/1/1056-01).

The funders had no role in study design, data collection and analysis, decision to publish, or preparation of the manuscript.

Copyright: @ 2021 Arold ST. This is an open access article distributed under the terms of the Creative Commons Attribution License, which permits unrestricted use, distribution, and reproduction in any medium, provided the original work is properly cited.

How to cite this article: Arold ST. Intrinsic negative feedback as a limiting factor for the evolution of higher forms of intelligence [version 3; peer review: 2 approved] F1000Research 2021, 9:34 https://doi.org/10.12688/f1000research.22039.3

First published: 23 Jan 2020, 9:34 https://doi.org/10.12688/f1000research.22039.1 


\section{REVISED Amendments from Version 2}

This new version clarifies that the definition I use for human (or human-like) intelligence (termed $\mathrm{HI}$ in my manuscript) has been specifically formulated to fit the purpose of my manuscript. It should not be seen as an alternative definition for "general intelligence".

I have also added additional references.

Please see my reply to Prof. Sternberg's comments for more details and justifications.

Any further responses from the reviewers can be found at the end of the article

\section{Introduction}

Our particular type of intelligence is commonly believed to be the central feature that has allowed humans to become one of the most abundant mammals on Earth. Yet, although our intelligence is such a powerful and generally useful trait, it has never been paralleled in any other organism. As an explanation, we generally assume that our cognitive uniqueness results from the major difficulty in achieving the required level of developmental sophistication. And after billion years of competitive evolution, we humans were the first species advanced enough to surmount these difficulties and to accumulate all features necessary for achieving this higher intelligence. Here, I investigate this conjecture and its underlying assumptions. For this purpose, I deliberately and necessarily adopt a very narrow anthropocentric definition for human (or human-like) intelligence (HI) as "the intelligence that enables development of advanced technology-based societies like ours". Within this definition, 'intelligence' does not only refer to 'computing power', but also to the full ensemble of cognitive and character traits required to reach such a state. This definition is specific for "HI", formulated to fit the purpose of my manuscript. It should not be seen as an alternative definition for "general intelligence".

\section{A race towards higher intelligence?}

First, underlying this conjecture is a worldwide trend toward ever higher levels of intelligence, a trend that reached a critical threshold in the Pliocene when HI was finally developed in humans ${ }^{2,3}$. Evidence for such a trend is weak. While a global trend toward bigger brains has been observed in several instances, it does not hold true for all taxonomic levels ${ }^{2-5}$. It is unclear if this trend, which is weak and concomitant with an increase in diversity and afflicted by exceptions, is the result of directed evolution or random drift ${ }^{4}$. It also appears that this trend, if it indeed exists, is a much weaker driving force than are the forces that are linked to adaptation to a specific niche ${ }^{6}$.

\section{Linear evolution versus iterative adaptation}

The argument that Homo sapiens was the first to reach an HI-enabling level of developmental sophistication evokes a linear view of evolution that posits that basal forms develop into ever more advanced and intelligent organisms. However, paleontologic and genetic evidence shows that evolution is not an orderly step-by-step advancement; rather, it is characterised by consecutive waves of radiation of species (many of which become dead-end groups) into the same ecological niches? During this iterative process of consecutive adaptations, many sophisticated characteristics (such as vision, flight, echolocation, burrowing or re-adaptation to water) evolved several times, successively and independently, in different species $^{7-12}$ (Figure 1). Even mammalian hallmark features, such as the middle ear and tribosphenic (crushing and biting) molars, evolved not once but several times in different mammals ${ }^{7,13}$. This convergence level of evolution indicates that the geological time scale is sufficiently large compared to the biological reproduction and diversification rates that even complex anatomical and molecular features can be reproduced if they enhance the chances of a species' survival. Since our type of intelligence appears to be such a powerful and versatile development for the survival of a species, why has no other organism acquired HI?

\section{Lack of suitable environment?}

The previous section highlights the importance of ecological niches in directing the evolution of specific traits. Hominid evolution is indeed likely to have been driven by particular changes or variability in climate, although the exact nature and importance of these changes are a matter of debate ${ }^{14}$. More specifically concerning our cognition, coping with environmental changes has been suggested as a factor that drives brain evolution, within the cognitive buffer hypothesisis. Nonetheless, the climate changes evoked are not sufficiently rare or specific to be a serious limiting factor for the development of $\mathrm{HI}$ in other species. Moreover, similar environments, or environmental changes, have failed to promote the emergence of $\mathrm{HI}$ in other species. Additionally, if the competitive advantage and driving force of $\mathrm{HI}$ development lies in overcoming dependence of the environment ${ }^{15}$, or enables favourable niche construction $^{16}$, then this advantage would profit many species, and hence is not a limiting factor. Finally, the rapid and almost worldwide spread of Homo species shows that its type of intelligence can be used under many conditions and is not an adaptation limited to a unique environmental ecological niche or geological condition that existed only at the precise time and place of the origin of humans.

\section{Brain size, structure and complexity}

Compared to the brain structure and brain-body ratios of other animals, the human brain is, of course, exceptionally big and complex in terms of layered structure, interconnectedness and neuronal diversity. But is its structure unique and sophisticated enough to justify that our brain capacity was never paralleled through adaptation and convergent evolution? Accumulated evidence suggests that the answer is no. Neuroscientists have established that the brain structures of birds and mammals are never simple. The anatomical differences between species reflect the animals' adaptations to a particular niche, not the lack of sufficient time for their brains to become more complex ${ }^{6}$. In fact, the human brain is less evolved (in the sense of being altered with respect to the brains of stem mammalians) than the ayeaye (Daubentonia madagascariensis) brain ${ }^{17}$. Rather, the human brain is more or less a scaled-up version of a non-human primate brain $^{18}$. Its size and structure are principally the result of simply extending the high growth rate of foetal brains into early infancy ${ }^{19-22}$. This prolonged growth was achieved by the 

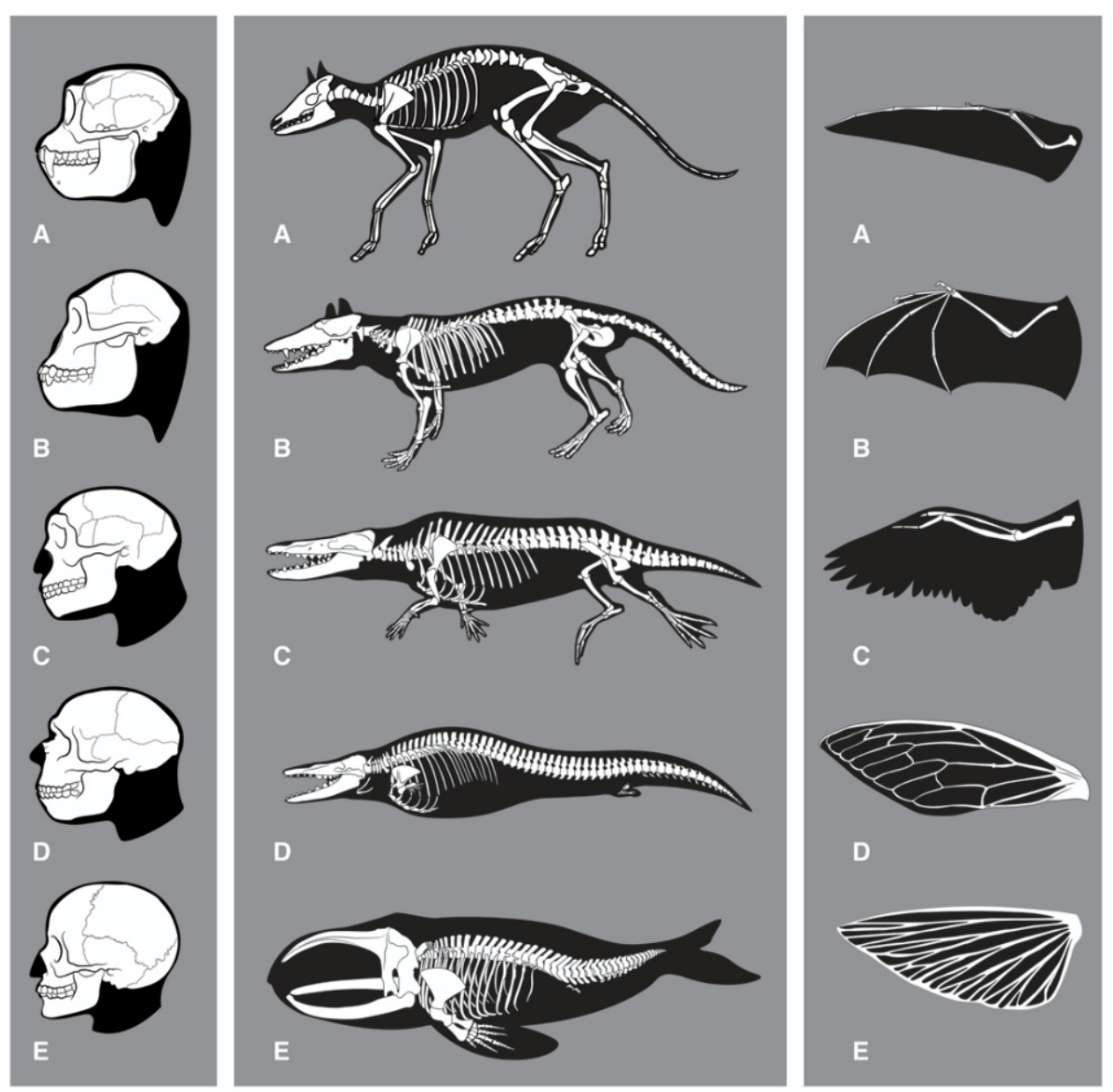

Figure 1. Evolution of features related to thinking, swimming and flying. Left: Skeletal changes associated with evolution of the human brain. (A) Rhinopithecus (stub-nosed monkey), (B) Australopithecus, (C) Homo erectus, (D) Homo neanderthalensis, (E) Homo sapiens. Note that also other anatomical features are likely to be required for human intelligence (HI) (for example those enabling tool-use). Middle: Skeletal changes associated with the evolution of whales. Adaptations to the aquatic habitat include: Removing of external appendices (ears, genitals, hind legs); changes of skin; loss of hair; stream-lined body shape; development of a sealable blowhole on top of the head, flippers, tail flukes and a dorsal fin; evolution of a flexible rib cage; increased organ-selective oxygen storage in the body; increased anaerobic capacity of muscles; capacity to slow down pulse (bradycdia); capacity of resting ('sleeping') one half of the brain at a time; tail-first birth of babies; development of echolocation (odontoceti). (A) Diacodexis, (B) Pakicetcus, (C) Ambulocetus, (D) Dorudon, (E) Balaena. Taken from 23. Right: Convergent evolution for wing development. (A) pterosaurus, (B) bat, (C) bird, (D) insect, (E) flying fish. Note that although vertebrate forelimbs adaptions are functionally convergent, they are not anatomically convergent. Insect wings are formed from a totally different organ. Although flying and re-adaptation to water are not equivalent to the development of HI on all levels, they might serve as comparison in terms of 'evolutionary difficulty' with respect to the required profound reshaping or combination of existing structures (including alterations in bone structure, muscle, metabolism, respiration, vision or connective tissue).

modification of gene expression patterns of a few regulators ${ }^{24,25}$, a common mechanism for species differentiation (for example, $\left.{ }^{26-28}\right)$. Of course, the scaling-up of the primate brain did not linearly affect all components, and the enhanced increase of the neocortex was certainly key to generating HI. Yet, altering the gene expression pattern of a single transcription factor (Pax6) in mice to a human-like pattern suffices to obtain a primatelike increase in neural progenitors, notably basal radial glia, and ultimately in the number of neurons produced, which is thought to underlie the evolutionary expansion of the neocortex ${ }^{25}$. Human brain performance was additionally boosted by slightly increasing the ratio of astrocytes to neurons, a tendency already observed in other higher mammals ${ }^{29}$. This ratio present in humans is, however, similar to that seen in other primates $^{18}$. In terms of genetic modifications, the development of the human brain therefore appears to be based on extending already existing features through gradual and common mechanisms, rather than being the result of a genetic quantum leap. 
Such genetic evolutionary mechanisms are not restricted to primates. For example, it was the expansion of a handful of gene families and genome rearrangements in an otherwise standard invertebrate gene background that allowed octopuses to produce profound morphological and neurological changes ${ }^{30}$. These changes sufficed to produce a large and sophisticated nervous system in addition to profound morphological innovations for their vision, arms and embryogenesis, resulting in a dramatically increased cognition and behavioural richness in octopuses as compared to worms, molluscs and other lophotrochozoans. Thus, the emergence of our highly specific human cognition has been achieved through continuity on a genetic level, accessible in principle also to other species.

\section{Convergent evolution of intelligence}

Since the human brain originated through extensions of primate brain features, can HI originate only from the brain structure of apes (Hominoidea)? If this is the case, then apes would have had to evolve first before HI occurred, and this condition may help to explain the late and single occurrence of this type of intelligence. However, it was not only other primate species (such as capuchins), but also elephants, cetaceans and certain birds that independently evolved cognitive and social characteristics that are very similar to those of apes (including self-consciousness, grief, altruism, play, envy, compassion and abstract numerical competence), despite having fundamentally different brain architectures ${ }^{31-37}$. Although the overall brain architecture differs, convergent evolution can produce obligatory neuronal adaptations in unrelated genera. For example, von Economo neurons, which have been related to complex social behaviour, have independently evolved in primates, whales, elephants and racoons ${ }^{38}$. Because of neuroplasticity, such convergent evolution is even easier for the brain than for other organs. Accordingly, our particular intelligence is not based on unique characteristics; rather, it arises from a combination and enhancement of abilities found in other vertebrates ${ }^{39}$. In fact, our large brains and particular intelligence appear to be independent of our ape phylogeny; rather, they result from convergent processes similar to those that produced avian and New World monkey brains ${ }^{40}$. Taken together with the finding that in some cognitive tasks monkeys can be outperformed by other animals, including birds ${ }^{41,42}$ and even fish $^{43}$, scientific evidence does not support the unilinear view that only the brain structure of apes is suited to produce HI.

\section{Overcoming the high energy requirement}

Big brains are energetically costly organs. Moreover, because of its neuronal density and neuron/glial cell ratio, a human brain requires more energy than for example a rodent brain of the same size $\mathrm{s}^{44}$. Could the unique development of $\mathrm{HI}$ in humans be explained by our species being the only one capable of coping with the high metabolic demand of a brain required for generating $\mathrm{HI}$ ?

There are many ways of overcoming metabolic limitations. These include shifting to higher-energy food sources (such as nuts, honey or meat, especially from invertebrates like molluscs or insects); external transformation of food to a more edible state (through grinding, fermentation, cooking or other types of food processing); more efficient use of existing food sources through simple tools and/or strategies (for transport, butchery, or storage); adaptive genetic changes to improve the digestive system (and associated microflora), or to diminish body energy expenditure [such as changes in skin coating (e.g. fur or feathers) or locomotion (e.g. bipedalism, architecture of limbs and feet)]; increasing foraging efficiency through intra-species organisation (e.g. for hunting, gathering, carcass defence or food processing); or shifting to habitats richer in high-protein food sources. A subset of these strategies was sufficient to provide the increased energy demand throughout hominid evolution (see ref. 45 and discussion therein). These strategies (including the cognitive capacities to $\operatorname{cook}^{46}$ ) do not require features that are only found in humans, making sufficient subsets of them also accessible to other species. Moreover, as the brain of an organism becomes bigger and more powerful, the enhanced cognitive capacities will increasingly enable this organism to implement strategies to enhance energy intake. The cognitive pay-offs of big brains should therefore allow alleviation of the associated energetic cost. In conclusion, while the high energy demand of an HI-capable brain is an important roadblock for the development of HI, the physical and intellectual strategies required to overcome this hurdle are not only accessible to the human body plan. And although the adaptations required to sustain a big brain are profound, they are paralleled, for example, by the metabolic and physical adaptations required for powered flight, which has evolved multiple times in different taxa (Figure 1).

\section{Language and intelligence}

It appears safe to assume that HI would not be possible without a powerful language. Compared to other animals, the human language appears to distinguish itself in many ways, including the large amount of symbols used ('vocabulary'), the complex compositional, hierarchical and recursive syntax, and the need to learn the complete language from scratch during an individual's lifetime ${ }^{47}$. It has been suggested that language evolution and efficient tool use have stimulated each other mutually ${ }^{48}$. More generally, it might be that the way of thinking that our language enables is what makes us human ${ }^{49,50}$. It is therefore important to discuss whether the uniqueness of $\mathrm{HI}$ can be explained by the uniqueness of our language.

Adopting the particular viewpoint of this essay, we then have to ask whether the development of HI-supporting language would be possible for other species. Let us first consider the requirements for producing a sufficient vocabulary. On a purely anatomical or mechanistic level, a HI-supporting language might be any sort of expression not limited to speech (e.g. twitter, tapping, signs, gestures, visual cues) that can produce a sufficient vocabulary space. This requirement does not seem to be restrictive. Moreover, some evidence suggests that the increase in human brain size preceded the development of finely articulated speech $^{51}$. It was therefore not the pre-existence of an articulate vocalisation, but only a physiological potential for it, that was sufficient for allowing the evolution of HI in humans.

Let us now consider language syntax and acquisition with respect to human uniqueness. It has indeed been proposed that 
such properties of the human language are neither specific to language nor to humans: Already Darwin had recognized the similarity between birdsong and human speech $^{52}$. The process and the underlying neuronal circuits by which a young bird learns the songs from an adult 'tutor' show indeed strong parallels with speech acquisition in human infants on behavioural, neural and genetic levels ${ }^{53,54}$. Moreover, common genetic key players have been identified, including the FOXP2 gene $^{55,56}$. The hierarchical combination of 'words' bears resemblance to semantic combinations in primate calls or compass headings in honeybees ${ }^{57,58}$. It has therefore been suggested that the human language results from the combination of separate, pre-existing simple systems that may have evolved for other functional tasks ${ }^{59}$.

In conclusion, while the exact behavioural, neural and molecular links between language, intelligence and behaviour are still emerging and under debate, significant characteristics of human language appear accessible to other species, including nonprimates, and are not tied to a specific brain anatomy or size. Thus, current evidence suggests that the capacity for developing a HI-supporting system of communication is not a feature strictly limited to humans or the human brain anatomy or speech production.

\section{Is there an essential combination of features?}

HI poses requirements to a candidate species beyond developing and coping with the appropriate brain anatomy, associated energy demands and language. For example, HI would be most useful in an organism that can use tools and has a complex social system that allows transmitting and accumulating acquired knowledge and culture. Importantly, these individual features synergise with each other (e.g. 48,60) and may need to evolve as an ensemble. While producing one individual feature may not be particularly difficult, and although combination of pre-existing traits is a common evolutionary mechanism, it could still be that the combined likelihood of assembling all required features in one species is sufficiently small to explain HI's uniqueness. Unfortunately, it is currently impossible (i) to test which sub-ensemble of characteristics is a strict prerequisite for HI development (as opposed to characteristics which can be developed en route towards $\mathrm{HI}$ ), and (ii) to quantitate the likelihood for the occurrence of such an ensemble in one animal. Thus, we can only approximate this question by asking if the presence of HI-enabling features and capacities was uniquely found in early hominids. In other words, is HI development such a rare event because of a shortage of suitable candidate species?

Tool use is well documented in many animals and is neither restricted to primates (it has been observed in sea otters, elephants and dolphins) nor to mammals (more than 120 cases of tool use in 104 bird species have been reported $)^{61-64}$. Many species of dinosaurs, Triassic archosaurs or marsupials were/are bipeds with free, articulate limbs, affording them great potential for tool use $\mathrm{e}^{10}$, many relatively small, birdlike dinosaurs, such as Troodon, possessed a grasping hand with an opposable digit $^{65}$, whereas dolphins use tools even though they have no limbs to grasp the tools. Child caring, intra-species communication and even cultural transmissions are documented not only in primates, but also other vertebrates (such as meerkats and fish) and maybe even in insects (e.g., teaching behaviours have been suggested in ants ${ }^{66}$. Social complexity as a potential driver for enhanced brain size and social intelligence (the "social complexity hypothesis ${ }^{60}$ ) has been reported in diverse non-human vertebrates (including lemurs, dolphins, parrots and spotted hyenas $^{67-71}$, suggesting that social complexity can drive brain evolution in diverse species. With respect to the importance of language, as discussed above, many species possess means of communication which might have the potential to evolve, within a few million years, into a sufficiently complex vocabulary and syntax to synergise with an emerging cognition. Thus, great apes, dolphins and some bird species have reached a high sophistication in terms of vocabulary, semantics, syntax and symbolic references, together with their cognitive capacities ${ }^{34,72,73}$

Finally, development of HI does not appear restricted to organisms with sizes similar to humans. Although the brain-tobody size (encephalization) appears to correlate roughly with cognitive capacity, brains do not have to be above a particular absolute size to produce high levels of intelligence ${ }^{74}$. For example, despite having a smaller brain than chimpanzees and australopithecines, Homo floresiensis, the Indonesian smallbodied 'Hobbit' species, was capable of manufacturing tools as advanced as those produced by Homo species with a three times larger brain $^{75}$. Moreover, the complex cognitive abilities of some bird species (including tool use, episodic-like memory, predicting the behaviour of conspecifics based on own experiences and self-recognition) are produced by brains that are less than $10 \mathrm{~g}$ in weight ${ }^{76}$. Thus, HI candidate species are not limited to those animals that have comparable sizes to humans.

In summary, while it is currently impossible to evaluate the evolutionary likelihood for combining the required features into a HI-capable animal, it is clear that many organisms besides humans readily combined several characteristics that could support HI (such as tool use, cultural transmissions, size of groups or body). During development towards HI, these characteristics can in principle be developed further, and completed, as it has been the case in our lineage. And although the combination of features found in early hominids before brain expansion (i.e. free limbs, capacity for grasping, social structure and tool use) are not common, they are not unique either, and it is therefore unlikely that HI was developed only once because no other species would have been a suitable candidate.

\section{HI as an intrinsically unfavourable trait}

According to the findings discussed above, the development of HI is not complex enough to fully explain that it has never been reproduced in any other species than Homo sapiens. If HI were within reach of convergent evolution, as my survey suggests, then an intriguing possible explanation for the fact that $\mathrm{HI}$ nonetheless evolved only once would be that $\mathrm{HI}$ is normally an overall unfavourable feature that is sooner or later sanctioned by selection. Yet, the physical constraints associated 
with HI appear to be manageable, and the human body is not special enough to suggest that no other organism could have evolved to cope with those constraints. If there is an unfavourable aspect of $\mathrm{HI}$, then it must arise from somewhere other than these physical constraints.

Could it be that some of the same mental and behavioural characteristics that are necessary for the development of $\mathrm{HI}$ might become increasingly unfavourable as a species evolves towards HI, creating a negative feedback loop? There is certainly a positive correlation between the proximity of species to HI and the emotional and structural complexity of their individuals and societies (where emotional complexity is defined as having emotional experiences that are broad in range and well differentiated). This correlation is apparent in species with very different brain structures and sizes (cetaceans, elephants, apes, Cebus monkeys and some birds ${ }^{31,32,34,73,77}$ ), suggesting that it is an intrinsic hallmark of $\mathrm{HI}$.

Behavioural studies on capuchin monkeys may provide an anecdotal illustration of this concept. These New World monkeys independently evolved an intelligence with certain characteristics similar to that of great apes and humans ${ }^{34}$. Owing to their particular amalgam of a strong cognitive capacity and an emotional and almost pugnacious character, capuchins have developed tools and strategies that allow them to forage for food that is impossible for most other animals to attain. Their complex social system stimulates learning, the emergence of culture and the establishment of an efficient communal defence against predators ${ }^{34}$. This type of intelligence, however, produces a society in which individuals spend an excessive amount of time engaged in complex nonproductive or even counterproductive social activities (such as allomothering, non-reproductive sex, apparently non-profit harassment of other animals or harmful "games" such as eyeball poking) and in violent or lethal aggression (the major cause of death for a capuchin monkey is an altercation with another capuchin monkey) ${ }^{34}$. If a further increase in the monkey's para-HI intelligence requires increasing the same behavioural and character features that cause counterproductive comportments, then the resulting negative feedback may block development of HI. Conversely, if a candidate species deviates too much from these characteristics, then HI may not result, despite a suitable cognitive power.

In humans, an illustration for the negative effects of HI-associated cognitive complexity is provided by the high incident of cognitive diseases. For example, schizophrenia has been suggested to be 'the price that Homo sapiens pays for language ${ }^{97}$. It has also been shown in animals and humans that the more polymorphic tri-nucleotide repeats are present in the gene $H d h$ (which codes for the protein huntingtin), the higher the capacity of this gene to promote the neural tube formation required for complex brains, but also the higher the probability to develop fatal neurodegenerative Huntington's disease $^{79}$. More generally, the genes regulating synaptogenesis and neuronal circuit formation have been associated with an increased risk of mental illnesses ${ }^{80,81}$. Based on autism spectrum disorders, it was suggested that brain networks involved in HI-required cognitive skills, such as language and complex social behaviour, have less compensatory mechanisms, and are hence less robust, than more ancient biological functions ${ }^{81}$. As a final example, the rise of complex diseases (i.e. diseases caused by a combination of genetic, environmental and lifestyle factors) has been linked to the rapid genetic, geographic, dietary and cultural changes associated with $\mathrm{HI}^{82}$. The impact of neurological pathologies increases in high-cognition species, and cumulates in humans, where currently about one in four individuals is affected (source: World Health Organization, 2001). The incidence of mental disorders continues to grow, and with it its individual, social and economic impacts (World Health Organization, 2019). Accordingly, mental health costs are now the highest single source of global economic burden in the world ${ }^{83}$. Thus, the increased instability and lability inherently associated with a trajectory towards HI might produce a negative feedback loop counteracting the evolution of HI.

Additionally, there might be a different type of negative feedback loop intrinsic to $\mathrm{HI}-\mathrm{HI}$ might simply allow a species to become so successful in exploiting food resources that these resources become exhausted. A non-human example is provided by long-tailed macaques living on islands in Thailand. These monkeys developed stone tools that allow foraging on shellfish. Over time, however, this technology is so efficient that the macaques severely deplete the shellfish populations on the islands. This triggers a feedback loop where diminishing prey size results in reduced stone $\operatorname{size}^{84}$. The authors suggest that continuation of this pattern leads to a point where this technology is no longer beneficial or useful to the island macaques, ultimately leading to extinguishing of this technology.

\section{Conclusion and outlook}

A specie's intelligence is a multidimensional characteristic adapted to maximise the specie's survival. My analysis suggests that the genetic adaptations required for development of HI might have been within reach of more species than only Homo sapiens. However, all other species that have radiated into high-intelligence niches have stagnated at sub-HI levels, often for many million years; only the Homo lineage has crossed this barrier in a very short time. The fact that no other species has reached HI appears unsatisfactorily explained by physical constraints of HI. A possible additional explanation may be that the main barrier towards HI is not only the development of the required physical assets, but also that negative feedback from social, behavioural and neuroanatomical complexity, as well as negative environmental feedback make the development of $\mathrm{HI}$ increasingly unfavourable.

How could Homo overcome this barrier? I speculate that key features may have been that our brain originated very rapidly as an exaptation, not adaptation ${ }^{85}$, together with an ensemble of favourable anatomical changes (e.g., skeletal proportions, dental function and the respiratory system), in a species with extremely low population densities (typically about 10 individuals per $100 \mathrm{~km}^{286}$ ). This origin may have initially allowed Homo to develop the brain structure required for HI, while circumventing or sufficiently attenuating immediate 
negative feedback associated with the use of $\mathrm{HI}$ in a socially complex populous environment where intra-species competition is the biggest threat.

However, as we are becoming overly abundant, and use our brain to its full potential to succeed within our complex societies, the negative side effects become increasingly challenging. Despite the development of psychological, moral, behavioural ('selfdomestication'), pharmacological and technological solutions, we are knowingly and consciously pursuing our unsustainable development that is rapidly destroying the resources upon which we critically depend ${ }^{87-89}$. However, globally engaging in the actions required to change our current trajectory and achieve long-term sustainability appears contrary to human nature.

\section{Data availability}

No data are associated with this article.

\section{Acknowledgements}

I thank all colleagues and anonymous reviewers who have contributed to this manuscript through stimulating discussions, and by providing comments and counterarguments. I thank KAUST Research Support Services for editorial assistance (Virginia. A. Unkefer) and for figure design and preparation (Ivan Gromicho). Research reported in this publication was supported by the King Abdullah University of Science and Technology (KAUST).
1. Sternberg RJ: The augmented theory of successful intelligence. In R. J. Sternberg (Ed.), Cambridge handbook of intelligence (2nd ed). Cambridge University Press. 2020; 2: 679-708. Publisher Full Text

2. Jerison HJ: Brain evolution: new light on old principles. Science. 1970; 170(3963): 1224-1225

PubMed Abstract | Publisher Full Text

3. Kruska DC: On the evolutionary significance of encephalization in some eutherian mammals: effects of adaptive radiation, domestication, and feralization. Brain Behav Evol. 2005; 65(2): 73-108. PubMed Abstract | Publisher Full Text

4. Finarelli JA, Flynn JJ: The evolution of encephalization in caniform carnivorans. Evolution. 2007; 61(7): 1758-1772. PubMed Abstract | Publisher Full Text

5. Montgomery SH, Geisler JH, McGowen MR, et al:: The evolutionary history of cetacean brain and body size. Evolution. 2013; 67(11): 3339-3353. PubMed Abstract | Publisher Full Text

6. Marino L, Hof PR: Nature's experiments in brain diversity. Anat Rec A Discov Mol Cell Evol Biol. 2005; 287(1): 997-1000. PubMed Abstract | Publisher Full Text

7. Luo ZX: Transformation and diversification in early mammal evolution. Nature. 2007; 450(7172): 1011-1019. PubMed Abstract | Publisher Full Text

8. Varricchio DJ, Martin AJ, Katsura Y: First trace and body fossil evidence of a burrowing, denning dinosaur. Proc Biol Sci. 2007; 274(1616): 1361-1368. PubMed Abstract | Publisher Full Text | Free Full Text

9. Nesbitt SJ, Norell MA: Extreme convergence in the body plans of an early suchian (Archosauria) and ornithomimid dinosaurs (Theropoda). Proc Biol Sci. 2006; 273(1590): 1045-1048.

PubMed Abstract | Publisher Full Text | Free Full Text

10. Brusatte SL, Benton MJ, Ruta M, et al.: Superiority, competition, and opportunism in the evolutionary radiation of dinosaurs. Science. 2008 321(5895): 1485-1488.

PubMed Abstract | Publisher Full Text

11. Xu X, Zheng X, Sullivan C, et al.: A bizarre Jurassic maniraptoran theropod with preserved evidence of membranous wings. Nature. 2015; 521(7550): 70-73. PubMed Abstract | Publisher Full Text

12. Wang $\mathrm{M}, \mathrm{O}$ 'Connor JK, Xu X, et al:: A new Jurassic scansoriopterygid and the loss of membranous wings in theropod dinosaurs. Nature. 2019; 569(7755): 256-259.

PubMed Abstract | Publisher Full Text

13. Martin T, Ruf I: Paleontology. On the mammalian ear. Science. 2009; 326(5950): 243-244. PubMed Abstract | Publisher Full Text

14. Gibbons A: Human evolution. How a fickle climate made us human. Science. 2013; 341(6145): 474-479. PubMed Abstract | Publisher Full Text

15. Sol D: Revisiting the cognitive buffer hypothesis for the evolution of large brains. Biol Lett. 2009; 5(1): 130-133. PubMed Abstract | Publisher Full Text | Free Full Text
16. Kendal J, Tehrani JJ, Odling-Smee J: Human niche construction in interdisciplinary focus. Philos Trans R Soc Lond B Biol Sci. 2011; 366(1566): 785-92. PubMed Abstract | Publisher Full Text | Free Full Text

17. Kaufman JA, Ahrens ET, Laidlaw DH, et al.: Anatomical analysis of an ayeaye brain (Daubentonia madagascariensis, primates: Prosimii) combining histology, structural magnetic resonance imaging, and diffusion-tensor imaging. Anat Rec A Discov Mol Cell Evol Biol. 2005; 287(1): 1026-1037. imaging. Anat Rec A Discov Mol Cell Evol Biol.
PubMed Abstract | Publisher Full Text

18. Azevedo FA, Carvalho LR, Grinberg LT, et al.: Equal numbers of neuronal and nonneuronal cells make the human brain an isometrically scaled-up primate brain. J Comp Neurol. 2009; 513(5): 532-541. PubMed Abstract | Publisher Full Text

19. Bush EC, Allman JM: The scaling of frontal cortex in primates and carnivores. Proc Natl Acad Sci U S A. 2004; 101(11): 3962-3966. PubMed Abstract | Publisher Full Text | Free Full Text

20. Leigh SR: Brain growth, life history, and cognition in primate and human evolution. Am J Primatol. 2004; 62(3): 139-164. PubMed Abstract | Publisher Full Text

21. Semendeferi $\mathrm{K}$, Lu A, Schenker N, et al.: Humans and great apes share a large frontal cortex. Nat Neurosci. 2002; 5(3): 272-276. PubMed Abstract | Publisher Full Text

22. Sherwood CC, Stimpson CD, Raghanti MA, et al.: Evolution of increased glianeuron ratios in the human frontal cortex. Proc Natl Acad Sci U SA. 2006; 103(37): 13606-13611.

PubMed Abstract | Publisher Full Text | Free Full Text

23. Barton NH, Briggs DEG, Eisen JA, et al.: Evolution. Cold Spring Harbor Laboratory Press. 2007. Reference Source

24. Somel M, Liu X, Tang L, et al.: MicroRNA-driven developmental remodeling in the brain distinguishes humans from other primates. PLOS Biol. 2011; 9(12): e1001214.

PubMed Abstract | Publisher Full Text | Free Full Text

25. Wong FK, Fei JF, Mora-Bermúdez F, et al.: Sustained Pax6 Expression Generates Primate-like Basal Radial Glia in Developing Mouse Neocortex. PLOS Biol. 2015; 13(8): e1002217.

PubMed Abstract | Publisher Full Text | Free Full Text

26. Abzhanov A, Protas M, Grant BR, et al.: Bmp4 and morphological variation of beaks in Darwin's finches. Science. 2004; 305(5689): 1462-1465. PubMed Abstract | Publisher Full Text

27. Erickson GM, Rogers KC, Yerby SA: Dinosaurian growth patterns and rapid avian growth rates. Nature. 2001; 412(6845): 429-433. PubMed Abstract | Publisher Full Text

28. Bhullar BA, Marugán-Lobón J, Racimo F, et al:: Birds have paedomorphic dinosaur skulls. Nature. 2012; 487(7406): 223-226. PubMed Abstract | Publisher Full Text

29. Nedergaard M, Ransom B, Goldman SA: New roles for astrocytes: redefining the functional architecture of the brain. Trends Neurosci. 2003; 26(10): 523-530.

PubMed Abstract | Publisher Full Text 
30. Albertin $C B$, Simakov $O$, Mitros $T$, et al:: The octopus genome and the evolution of cephalopod neural and morphological novelties. Nature. 2015 524(7564): 220-224.

PubMed Abstract | Publisher Full Text | Free Full Text

31. Shoshani J, Kupsky WJ, Marchant GH: Elephant brain. Part I: gross morphology, functions, comparative anatomy, and evolution. Brain Res Bull. 2006; 70(2): 124-157.

PubMed Abstract | Publisher Full Text

32. Marino L, McShea DW, Uhen MD: Origin and evolution of large brains in toothed whales. Anat Rec A Discov Mol Cell Evol Biol. 2004; 281(2): 1247-1255. PubMed Abstract | Publisher Full Text

33. Reiner $\mathrm{A}$, Yamamoto $\mathrm{K}$, Karten $\mathrm{HJ}$ : Organization and evolution of the avian forebrain. Anat Rec A Discov Mol Cell Evol Biol. 2005; 287(1): 1080-1102. PubMed Abstract | Publisher Full Text

34. Perry S: Manipulative Monkeys. The Capuchins of Lomas Barbudal. Harvard University Press. 2011

Reference Source

35. Scarf $D$, Hayne $H$, Colombo M: Pigeons on par with primates in numerical competence. Science. 2011; 334(6063): 1664

PubMed Abstract | Publisher Full Text

36. Schloegl C, Schmidt J, Boeckle $M$, et al.: Grey parrots use inferential reasoning based on acoustic cues alone. Proc Biol Sci. 2012; 279(1745): 4135-4142. PubMed Abstract | Publisher Full Text | Free Full Text

37. McNally L, Brown SP, Jackson AL: Cooperation and the evolution of intelligence. Proc Biol Sci. 2012; 279(1740): 3027-3034. PubMed Abstract | Publisher Full Text | Free Full Text

38. Allman JM, Tetreault NA, Hakeem AY, et al:: The von Economo neurons in the frontoinsular and anterior cingulate cortex. Ann N Y Acad Sci. 2011; 1225: 59-71.

PubMed Abstract | Publisher Full Text | Free Full Text

39. Roth G, Dicke U: Evolution of the brain and intelligence in primates. Prog Brain Res. 2012: 195: 413-430.

PubMed Abstract | Publisher Full Text

40. Lefebvre L: Brains, innovations, tools and cultural transmission in birds, non-human primates, and fossil hominins. Front Hum Neurosci. 2013; 7: 245 PubMed Abstract | Publisher Full Text | Free Full Text

41. Bolhuis JJ, Wynne CD: Can evolution explain how minds work? Nature. 2009; 458(7240): 832-833.

PubMed Abstract | Publisher Full Text

42. Emery NJ, Clayton NS: The mentality of crows: convergent evolution of intelligence in corvids and apes. Science. 2004; 306(5703): 1903-1907. PubMed Abstract | Publisher Full Text

43. Salwiczek LH, Prétôt L, Demarta L, et al.: Adult cleaner wrasse outperform capuchin monkeys, chimpanzees and orang-utans in a complex foraging task derived from cleaner--client reef fish cooperation. PLOS One. 2012 7(11): e49068.

PubMed Abstract | Publisher Full Text | Free Full Text

44. Fonseca-Azevedo K, Herculano-Houzel S: Metabolic constraint imposes tradeoff between body size and number of brain neurons in human evolution. Proc Natl Acad Sci U S A. 2012; 109(45): 18571-18576. PubMed Abstract | Publisher Full Text | Free Full Text

45. Wrangham RW, Jones JH, Laden G, et al.: The Raw and the Stolen. Cooking and the Ecology of Human Origins. Curr Anthropol. 1999; 40(5): 567-594. PubMed Abstract | Publisher Full Text

46. Warneken F, Rosati AG: Cognitive capacities for cooking in chimpanzees. Proc Biol Sci. 2015; 282(1809): 20150229.

PubMed Abstract | Publisher Full Text | Free Full Text

47. Hurford JR: Human uniqueness, learned symbols and recursive thought. Eur Rev. 2004; 12(4): 551-565.

Publisher Full Text

48. Greenfield PM: Language, Tools, and Brain - the Ontogeny and Phylogeny of Hierarchically Organized Sequential Behavior. Behav Brain Sci. 1991; 14(4): 531-550.

Publisher Full Text

49. Hauser MD, Chomsky N, Fitch WT: The faculty of language: what is it, who has it, and how did it evolve? Science. 2002; 298(5598): 1569-1579. PubMed Abstract | Publisher Full Text

50. Boeckx C: Biolinguistics: forays into human cognitive biology. J Anthropol Sci. 2013; 91: 63-89.

PubMed Abstract | Publisher Full Text

51. Capasso L, Michetti E, D'Anastasio R: A Homo erectus hyoid bone: possible implications for the origin of the human capability for speech. Coll Antropol. 2008; 32(4): 1007-1011.

PubMed Abstract

52. Darwin C: The descent of man, and selection in relation to sex. D. Appleton and company, New York. 1871. Publisher Full Text

53. Bolhuis JJ, Gahr M: Neural mechanisms of birdsong memory. Nat Rev Neurosci. 2006; 7(5): 347-357.

PubMed Abstract | Publisher Full Text

54. Mooney R: Neural mechanisms for learned birdsong. Learn Mem. 2009;
16(11): 655-669

PubMed Abstract | Publisher Full Text

55. Bolhuis IJ, Okanoya K, Scharff C: Twitter evolution: converging mechanisms in birdsong and human speech. Nat Rev Neurosci. 2010; 11(11): 747-759. PubMed Abstract | Publisher Full Text

56. Scharff C, Petri J: Evo-devo, deep homology and FoxP2: implications for the evolution of speech and language. Philos Trans R Soc Lond B Biol Sci. 2011; 366(1574): 2124-2140.

PubMed Abstract | Publisher Full Text | Free Full Text

57. Arnold K, Zuberbühler K: Language evolution: semantic combinations in primate calls. Nature. 2006; 441(7091): 303.

PubMed Abstract | Publisher Full Text

58. Riley JR, Greggers $U$, Smith $A D$, et al.: The flight paths of honeybees recruited by the waggle dance. Nature. 2005; 435(7039): 205-207. PubMed Abstract | Publisher Full Text

59. Miyagawa S, Berwick RC, Okanoya K: The emergence of hierarchical structure in human language. Front Psychol. 2013; 4: 71. PubMed Abstract | Publisher Full Text | Free Full Text

60. Dunbar RI: The social Brain hypothesis. Evolutionary Anthropology: Issues, News and Reviews. 1998; 6(5): 178-190. Publisher Full Text

61. Lefebvre L, Nicolakakis N, Boire D: Tools and brains in birds. Behav. 2002; 139: 939-973.

Publisher Full Text

62. Krützen M, Mann J, Heithaus MR, et al.: Cultural transmission of tool use in bottlenose dolphins. Proc Natl Acad Sci U S A. 2005; 102(25): 8939-8943. PubMed Abstract | Publisher Full Text | Free Full Text

63. Anderson JR: Gone fishing: tool use in animals. Biologist (London). 2002; 49(1): 15-18. PubMed Abstract

64. Rutz C, Klump BC, Komarczyk L, et al.: Discovery of species-wide tool use in the Hawaiian crow. Nature. 2016; 537(7620): 403-407. PubMed Abstract | Publisher Full Text

65. Russell DA, Dong Z: A nearly complete skeleton of a new troodontid dinosaur from the Early Cretaceous of the Ordos Basin, Inner Mongolia, People's Republic of China. Can J Earth Sci. 1993; 30(10): 2163-2173. Publisher Full Text

66. Franks NR, Richardson T: Teaching in tandem-running ants. Nature. 2006; 439(7073): 153.

PubMed Abstract | Publisher Full Text

67. Jolly A: Lemur social behavior and primate intelligence. Science. 1966; 153(3735): 501-506.

PubMed Abstract | Publisher Full Text

68. Connor RC: Dolphin social intelligence: complex alliance relationships in bottlenose dolphins and a consideration of selective environments for extreme brain size evolution in mammals. Philos Trans $R$ Soc Lond B Biol Sci. 2007; 362(1480): 587-602.

PubMed Abstract | Publisher Full Text | Free Full Text

69. Hobson EA, Avery ML, Wright TF: The socioecology of Monk Parakeets: Insights into parrot social complexity. The Auk. 2014; 131(4): 756-775. Publisher Full Text

70. Holekamp KE, Dantzer B, Stricker G, et al.: Brains, brawn and sociality: a hyaena's tale. Anim Behav. 2015; 103: 237-248. PubMed Abstract | Publisher Full Text | Free Full Text

71. Freeberg TM, Dunbar RIM, Ord TJ: Social complexity as a proximate and ultimate factor in communicative complexity. Philos Trans R Soc Lond B Biol Sci. 2012; 367(1597): 1785-1801.

PubMed Abstract | Publisher Full Text | Free Full Text

72. Marino L: Dolphin cognition. Curr Biol. 2004; 14(21): R910-911. PubMed Abstract | Publisher Full Text

73. Jarvis ED, Güntürkün $O$, Bruce $L$, et al:: Avian brains and a new understanding of vertebrate brain evolution. Nat Rev Neurosci. 2005; 6(2): 151-159. PubMed Abstract | Publisher Full Text | Free Full Text

74. Willemet R: Reconsidering the evolution of brain, cognition, and behavior in birds and mammals. Front Psychol. 2013; 4: 396. PubMed Abstract | Publisher Full Text | Free Full Text

75. Brumm A, Aziz F, van den Bergh GD, et al.: Early stone technology on Flores and its implications for Homo floresiensis. Nature. 2006; 441(7093): 624-628. PubMed Abstract | Publisher Full Text

76. Prior $\mathrm{H}$, Schwarz A, Gunturkun O: Mirror-induced behavior in the magpie (Pica pica): evidence of self-recognition. PLoS Biol. 2008; 6(8): e202. PubMed Abstract | Publisher Full Text | Free Full Text

77. Emery NJ, Seed AM, von Bayern AM, et al.: Cognitive adaptations of social bonding in birds. Philos Trans R Soc Lond B Biol Sci. 2007; 362 (1480): 489-505. PubMed Abstract | Publisher Full Text | Free Full Text

78. Crow TJ: Schizophrenia as the price that homo sapiens pays for language: a resolution of the central paradox in the origin of the species. Brain Res Brain Res Rev. 2000; 31(2-3): 118-129.

PubMed Abstract | Publisher Full Text

79. Lo Sardo V, Zuccato C, Gaudenzi G, et al.: An evolutionary recent 
neuroepithelial cell adhesion function of huntingtin implicates ADAM10Ncadherin. Nat Neurosci. 2012; 15(5): 713-721.

PubMed Abstract | Publisher Full Text

80. Yin J, Yuan Q: Structural homeostasis in the nervous system: a balancing act for wiring plasticity and stability. Front Cell Neurosci. 2014; 8: 439. PubMed Abstract | Publisher Full Text | Free Full Text

81. Toro R, Konyukh M, Delorme R, et al:: Key role for gene dosage and synaptic homeostasis in autism spectrum disorders. Trends Genet. 2010; 26(8): 363-372.

PubMed Abstract | Publisher Full Text

82. Gibson G: Decanalization and the origin of complex disease. Nat Rev Genet. 2009; 10(2): 134-140.

PubMed Abstract | Publisher Full Text

83. Bloom DE, Cafiero ET, Jané-Llopis E, et al.: World Economic Forum. Geneva. 2011.

84. Luncz LV, Tan A, Haslam M, et al.: Resource depletion through primate stone technology. eLife. 2017; 6: pii: e23647.

PubMed Abstract | Publisher Full Text | Free Full Text

85. Gould SJ: Exaptation: A crucial tool for evolutionary psychology. Journal of Social Issues. 1991; 47(3): 43-65. Publisher Full Text

86. Eriksson A, Betti L, Friend AD, et al:: Late Pleistocene climate change and the global expansion of anatomically modern humans. Proc Natl Acad Sci U S A. 2012; 109(40): 16089-16094. PubMed Abstract | Publisher Full Text | Free Full Text

87. Running SW: Approaching the Limits. Science. 2013; 339(6): 1276-1277. Publisher Full Text

88. Spratt D, Dunlop I: Existential climate-related security risk: A scenario approach. breakthroughonline.org.au. 2019. Reference Source

89. IPCC Sixth Assessment Report.

Reference Source 


\section{Open Peer Review}

\section{Current Peer Review Status:}

\section{Version 2}

Reviewer Report 31 August 2021

https://doi.org/10.5256/f1000research.28862.r92656

(C) 2021 Sternberg R. This is an open access peer review report distributed under the terms of the Creative Commons Attribution License, which permits unrestricted use, distribution, and reproduction in any medium, provided the original work is properly cited.

\section{Robert J Sternberg}

Department of Human Development, Cornell University, Ithaca, NY, USA

This interesting article speculates that the reason that human-type intelligence has not evolved in animals other than humans is that, ultimately, human intelligence is evolutionarily maladaptive. I believe the evidence supports the contention that human-type intelligence has many maladaptive aspects, but I am not convinced that the issue is evolutionary. Moreover, much depends on what one means by "human intelligence."

Perhaps the greatest problem with the article as it now stands is the definition of human intelligence. The definition in the article is "the intelligence that enables development of advanced technology-based societies like ours." This definition of intelligence is nonstandard and appears to be idiosyncratic relatively to standard definitions in the literature on intelligence, which tend to emphasize ability to learn, to adapt to the environment, to reason, and to process information efficiently and effectively (see definitions in Sternberg, 2020a).

The problem with the author's definition is that, for most of human history, there was no serious technology, at least not in the sense discussed in the article. If the goal of intelligence is to enable technology, then it has to be a recent one, not one that is evolutionarily-based. Technology as we know it today is too recent. Yet, the functions of intelligence actually do change over time (Greenfield, 2020) and are somewhat different as a function of culture and place (Sternberg, 2012). If technology is the goal, and so much of technology, as we now know, is destructive, it is no surprise that intelligence could be so dangerous, whether for evolutionary or other reasons.

The argument that human-type intelligence is maladaptive fits into an existing literature, which is largely not cited. Consider some examples. First, there are notions of intelligence that are simply different from the conventional one. For example, Sternberg (2019a, 2019b, 2021), in speaking of "adaptive intelligence," has argued that current human deployment of intelligence has become destructive not only to humans, but also to many other species. It is making the environment unsustainable for human life, a point with which the author apparently agrees. Second, there are broader notions of intelligence that suggest that the conventional view of intelligence is simply too narrow (Gardner, 2011; Sternberg, 2020b)—that there are multiple intelligences that do not fit 
conveniently into a single notion of general human intelligence. Third, there are theories of different kinds of intelligence that suggest that the conventional notion simply misses important aspects of human functioning, for example, emotional intelligence (e.g., Rivers et al., 2020), cultural intelligence (Ang et al., 2020), and practical intelligence (e.g., Hedlund, 2020). Fourth, there is the literature on wisdom, suggesting that humans need to apply their intelligence toward some kind of common good in order to thrive and create a sustainable future for themselves (e.g., Grossmann et al., 2020; Sternberg \& Karami, 2021). Finally, dystopian novels, such as Brave New World and 1984, have shown how human intelligence can lead to catastrophe as well as to success.

I think there is good evidence that human intelligence can be maladaptive. We scarcely need laboratory experiments when we look at how humans have handled crises such as global climate change, pollution, pandemics, and income disparity. But are the mechanisms gravitating against human intelligence in animals other than humans evolutionary? That is much less clear. No other species has, to our knowledge, come close to destroying the environment in the way humans have. There is no evidence that, because they started destroying the environment, evolution of human-like intelligence stopped. Moreover, for an evolutionary mechanism to take hold, the maladaptive trait would likely interfere with reproductive capability, but the people who destroy the Earth are mostly professionals, from politicians to corporate leaders, who are largely past reproductive age. By the time they succeed in destroying the environment, they are older. Serious mental illness, cited in the article, can interfere with reproduction, but it seems to apply to relatively small proportions of the human population.

Although I have some disagreements with the author, I agree that "Despite the development of psychological, moral, behavioural ('self-domestication'), pharmacological and technological solutions, we are knowingly and consciously pursuing our unsustainable development that is rapidly destroying the resources upon which we critically depend. However, globally engaging in the actions required to change our current trajectory and achieve long-term sustainability appears contrary to human nature."

Unless intelligence is deployed more adaptively, the world and the creatures in it are at serious risk (Sternberg, 2021). The question is whether we want to create a future for our progeny over many generations, or rather for many generations of viruses, bacteria, and, inevitably, the everpresent cockroaches.

\section{References}

Ang, S., Ng, K. Y., \& Rockstuhl, T. (2020). Cultural intelligence. In R. J. Sternberg (Ed.), Cambridge handbook of intelligence ( $2^{\text {nd }}$ ed., pp. 780-801). Cambridge University Press.

Gardner, H. (2011). Frames of mind: The theory of multiple intelligences. Basic Books.

Greenfield, P. M. (2020). Historical evolution of intelligence. In R. J. Sternberg (Ed.), Cambridge handbook of intelligence (pp. 916-939). Cambridge University Press.

Grossmann, I., Weststrate, N. M., Ardelt, M., Brienza, J. P., Dong, M., Ferrari, M., Fournier, M. A., Hu, C. S., Nusbaum, H. C., \& Vervaeke, J. (2020). The science of wisdom in a polarized world: Knowns and unknowns. Psychological Inquiry, 31(2), 103-133.

https://doi.org/10.1080/1047840X.2020.1750917 
Hedlund, J. (2020). Practical intelligence. In R. J. Sternberg (Ed.), Cambridge handbook of intelligence ( $2^{\text {nd }}$ ed., pp. 736-755). Cambridge University Press.

Rivers, S. E., Handley-Miner, I. J., Mayer, J. D., \& Caruso, D. (2020). Emotional intelligence. In R. J. Sternberg (Ed.), Cambridge handbook of intelligence ( $2^{\text {nd }}$ ed., pp. 709-735). Cambridge University Press.

Sternberg, R. J. (2012). Intelligence in its cultural context. In M. Gelfand, C. -Y. Chiu, and Y. -Y. Hong (Eds.), Advances in cultures and psychology (Vol. 2, pp. 205-248). New York: Oxford University Press.

Sternberg, R. J. (2019a). A theory of adaptive intelligence and its relation to general intelligence. Journal of Intelligence, https://doi.org/10.3390/jintelligence7040023

Sternberg, R. J. (2019b). Introduction to the Cambridge Handbook of Wisdom: Race to Samarra: The critical importance of wisdom in the world today. In R. J. Sternberg \& J. Glueck (Eds.), Cambridge handbook of wisdom (pp. 3-9). Cambridge University Press.

Sternberg, R. J. (2020a). The augmented theory of successful intelligence. In R. J. Sternberg (Ed.), Cambridge handbook of intelligence (2nd ed., Vol. 2, pp. 679-708). Cambridge University Press.

Sternberg, R. J. (Ed.) (2020b). Cambridge handbook of intelligence ( $2^{\text {nd }}$ ed.). New York: Cambridge University Press.

Sternberg, R. J. (2021). Adaptive intelligence: Surviving and thriving in a world of uncertainty. New York: Cambridge University Press.

Sternberg, R. J., \& Karami, S. (2021). What is wisdom? A unified 6P framework. Review of General Psychology, https://doi.org/10.1177/1089268020985509. Online Version.

\section{References}

1. Ang S, Ng K.Y., Rockstuhl T: Cultural intelligence. In R. J. Sternberg (Ed.), Cambridge handbook of intelligence (2nd ed.). Cambridge University Press. 2020. 780-801

2. Gardner H: Frames of mind: The theory of multiple intelligences. Basic Books. 2011.

3. Greenfield P. M: Historical evolution of intelligence. In R. J. Sternberg (Ed.), Cambridge handbook of intelligence. Cambridge University Press. 2020. 916-939

4. Grossmann I, Weststrate N, Ardelt M, Brienza J, et al.: The Science of Wisdom in a Polarized World: Knowns and Unknowns. Psychological Inquiry. 2020; 31 (2): 103-133 Publisher Full Text 5. Hedlund J: Practical intelligence. In R. J. Sternberg (Ed.), Cambridge handbook of intelligence (2nd ed.). Cambridge University Press. 2020. 736-755

6. Rivers S. E., Handley-Miner I. J., Mayer J.D., Caruso D.: Emotional intelligence. In R. J. Sternberg (Ed.), Cambridge handbook of intelligence (2nd ed.). Cambridge University Press. 709-735 7. Sternberg R. J.: Intelligence in its cultural context. In M. Gelfand, C. -Y. Chiu, and Y. -Y. Hong (Eds.), Advances in cultures and psychology (Vol. 2). Oxford University Press. 2012. 205-248 8. Sternberg RJ: A Theory of Adaptive Intelligence and Its Relation to General Intelligence.J Intell. 2019; 7 (4). PubMed Abstract | Publisher Full Text 
9. Sternberg R. J.: Introduction to the Cambridge Handbook of Wisdom: Race to Samarra: The critical importance of wisdom in the world today. In R. J. Sternberg.

10. Sternberg R. J.: The augmented theory of successful intelligence. In R. J. Sternberg (Ed.), Cambridge handbook of intelligence (2nd ed. Vol. 2). Cambridge University Press.2020. 679-708 11. Sternberg R. J: Adaptive intelligence: Surviving and thriving in a world of uncertainty. Cambridge University Press. 2021.

12. Sternberg R, Karami S: What Is Wisdom? A Unified 6P Framework. Review of General Psychology. 2021; 25 (2): 134-151 Publisher Full Text

Is the topic of the opinion article discussed accurately in the context of the current literature?

No

Are all factual statements correct and adequately supported by citations? Partly

Are arguments sufficiently supported by evidence from the published literature? Partly

Are the conclusions drawn balanced and justified on the basis of the presented arguments? Partly

Competing Interests: No competing interests were disclosed.

Reviewer Expertise: Intelligence

I confirm that I have read this submission and believe that I have an appropriate level of expertise to confirm that it is of an acceptable scientific standard.

Author Response 21 Sep 2021

Stefan Arold, King Abdullah University of Science and Technology, Thuwal, Saudi Arabia

I thank Prof. Sternberg for his thoughtful comments and criticism. These comments add greatly to the discussion I was hoping to engage in, and I welcome that the F1000 format allows publishing them alongside the manuscript. Below, I have represented passages from the reviewer's report in italics. My replies are below.

[...] I believe the evidence supports the contention that human-type intelligence has many maladaptive aspects, but I am not convinced that the issue is evolutionary. Moreover, much depends on what one means by "human intelligence." Perhaps the greatest problem with the article as it now stands is the definition of human intelligence. The definition in the article is "the intelligence that enables development of advanced technology-based societies like ours." This definition of intelligence is nonstandard and appears to be idiosyncratic relatively to standard definitions in the literature on intelligence, which tend to emphasize ability to learn, to adapt to the environment, to reason, and to process information efficiently and effectively (see definitions in Sternberg, 2020a). 
I agree that my definition of " $\mathrm{HI}$ " is non-standard, and acknowledge that this definition is "deliberately and necessarily [...] very narrow and anthropocentric" in my manuscript. Indeed, this definition is specific for " $\mathrm{HI}$ ", formulated to fit the purpose of my manuscript. It should not be seen as an alternative definition for "general intelligence".

The main purpose of my manuscript is to ask why our particular intelligence "has never been paralleled by any other organism". To position this discussion, I needed a definition of human intelligence that captures its unique attributes. However, many aspects of human intelligence (e.g. articulate communication, tool use, intentional cultivation of other species, intentional changes to the environment, culture and teaching) are also identified in other animals. In fact, our human intelligence appears to be a mix of cognitive traits that are already present in other animals. This observation is understandable because our brain is genetically and mechanistically not fundamentally different from the animal brains from which it derives. It is only the increased complexity and size of the human brain that enhance many of these traits. I also agree with Prof. Sternberg that intelligence is multidimensional and cannot be reduced to a single quantifying entity such as the IQ (e.g. Sternberg, 2019a). Hence, I chose the "development of technology-based societies" as the uniquely human hallmark of $\mathrm{HI}$. Were we to discover life on another planet, then it would be this "technology" aspect of intelligence that we would take (rightly or wrongly) as an indicator for an alien species to be our equal in terms of intelligence.

To clarify that my purpose-built definition of $\mathrm{HI}$ is not a general definition of (animal/human) intelligence I have added a sentence to the 'Introduction': "This definition is specific for "HI", formulated to fit the purpose of my manuscript. It should not be seen as an alternative definition for "general intelligence", and I now cite Sternberg, $2020 \mathrm{a}$.

The problem with the author's definition is that, for most of human history, there was no serious technology, at least not in the sense discussed in the article. If the goal of intelligence is to enable technology, then it has to be a recent one, not one that is evolutionarily-based. Technology as we know it today is too recent. Yet, the functions of intelligence actually do change over time (Greenfield, 2020) and are somewhat different as a function of culture and place (Sternberg, 2012). If technology is the goal, and so much of technology, as we now know, is destructive, it is no surprise that intelligence could be so dangerous, whether for evolutionary or other reasons.

In my manuscript, I am following the proposition of S.J. Gould that the human brain is an exaptation, not an adaptation (S.J. Gould, 1991; mentioned in my manuscript). Accordingly, advanced technology was not the evolutionary goal of $\mathrm{HI}$-just as powered bird flight was not the evolutionary goal of feathers, which have evolved many million years before birds took off from the ground (doi: 10.1016/j.tree.2019.04.018). Of course, a bird would not be able to fly without feathers, just as humans would not be able to produce technology without their brains. Yet, just as flapping or gliding with enlarged and specialised feathers may have increased the chances of survival in the ancestors of birds, the enlarged and specialised brains may have done the same for early homo species, for example by enhancing tool use or the control of fire. Intriguingly, many bird species coexist, and many species from other genera have developed highly sophisticated adaptations to allow powered flight without feathers. Conversely, only humans have developed "serious" technology, and only one human species survives today. Given that even complex beneficial 
features such as powered flight could arise many times during the past $\sim 200$ million years, why has no other species developed cognitive capabilities that ultimately produce an advanced technology?

The argument that human-type intelligence is maladaptive fits into an existing literature, which is largely not cited. Consider some examples. First, there are notions of intelligence that are simply different from the conventional one. For example, Sternberg (2019a, 2019b, 2021), in speaking of "adaptive intelligence," has argued that current human deployment of intelligence has become destructive not only to humans, but also to many other species. It is making the environment unsustainable for human life, a point with which the author apparently agrees. Second, there are broader notions of intelligence that suggest that the conventional view of intelligence is simply too narrow (Gardner, 2011; Sternberg, 2020b)-that there are multiple intelligences that do not fit conveniently into a single notion of general human intelligence. Third, there are theories of different kinds of intelligence that suggest that the conventional notion simply misses important aspects of human functioning, for example, emotional intelligence (e.g., Rivers et al., 2020), cultural intelligence (Ang et al., 2020), and practical intelligence (e.g., Hedlund, 2020). Fourth, there is the literature on wisdom, suggesting that humans need to apply their intelligence toward some kind of common good in order to thrive and create a sustainable future for themselves (e.g., Grossmann et al., 2020; Sternberg \& Karami, 2021). Finally, dystopian novels, such as Brave New World and 1984, have shown how human intelligence can lead to catastrophe as well as to success.

In my manuscript, I conclude that the development of the features needed to create $\mathrm{HI}$ (in my definition) is not "difficult" enough (in terms of converging evolution) to justify that no other species has ever paralleled our cognition. As a possible explanation for this conundrum, I then speculate that $\mathrm{HI}$ is an intrinsically unfavourable trait, meaning that "the same mental and behavioural characteristics that are necessary for the development of $\mathrm{HI}$ might become increasingly unfavourable as a species evolves towards $\mathrm{HI}$, creating a negative feedback loop".

In my manuscript, I based the current maladaptiveness of $\mathrm{HI}$ (in humans) on scientific data and predictions that state that our path is unsustainable and will lead to the "destruction of the resources onto which we critically depend". Hence, I have only cited (some of) these sources. Evidence for the unsustainable nature of our trajectory is accumulating rapidly, and I have now included the IPCC Sixth Assessment Report to add a most recent reference. The points raised by Prof. Sternberg are of course relevant, and I thank him for bringing additional aspects into this discussion. Indeed, given that our intelligence is so highly "adaptive" that it allowed us to invade and populate all continents, it is puzzling that our intelligence appears to be consciously maladaptive in the long run with respect to the environment that we have largely created ourselves. Homo sapiens is a great invasive species but lacks the wisdom to sustain itself, once there are no new territories to conquer? Is it the general nature of HI to destroy itself? This discussion extends beyond the focus of my manuscript (which is: are there intrinsic feedback loops that hamper the development of $\mathrm{HI}$ in other species?).

Concerning the literature on the different types of intelligence, I refer to my first reply above that I hope justifies why I have chosen a specific 'result-based' definition of HI (not general intelligence) for the purpose of this manuscript. 
The two dystopian novels deal with the author's imaginations for how future societies contain intellectual or moral aspects of human intelligence/behaviour. Destruction of the environment was not yet an issue. With this new imminent threat to humanity in plain view, what would Huxley's brave new world have been?

I think there is good evidence that human intelligence can be maladaptive. We scarcely need laboratory experiments when we look at how humans have handled crises such as global climate change, pollution, pandemics, and income disparity. But are the mechanisms gravitating against human intelligence in animals other than humans evolutionary? That is much less clear. No other species has, to our knowledge, come close to destroying the environment in the way humans have. There is no evidence that, because they started destroying the environment, evolution of human-like intelligence stopped. Moreover, for an evolutionary mechanism to take hold, the maladaptive trait would likely interfere with reproductive capability, but the people who destroy the Earth are mostly professionals, from politicians to corporate leaders, who are largely past reproductive age. By the time they succeed in destroying the environment, they are older. Serious mental illness, cited in the article, can interfere with reproduction, but it seems to apply to relatively small proportions of the human population.

I agree with Prof. Sternberg's comments and criticism above: I do not claim to have fully resolved the nature of the intrinsic negative feedback that I propose limits the development of $\mathrm{HI}$ in species. In fact, my main concern was to first acknowledge that "something" appears to be intrinsically limiting the development of $\mathrm{HI}$ in animals because producing the physiological framework for $\mathrm{HI}$ is not sufficiently "difficult" to justify that no other animal has ever reached it. As possible intrinsically limiting factors, I suggest the resulting fragilizing complexity (of organisms and the societies they form) and resource-depleting technology. I provide some illustrations of these concepts based on non-human animals (pre-HI, according to my definition) in my manuscript.

To tentatively explain that $\mathrm{HI}$ did evolve in humans, despite these intrinsically limiting mechanisms, I hypothesise that the human brain, and hence its HI capability, has developed rapidly as an exaptation in a low-abundance species, and thus has managed to circumvent these intrinsically limiting mechanisms. Will the same mechanisms now be able to push back future human descendants into a pre-HI stage? As mentioned in my manuscript, there are interesting signs of "self-domestication", and the relative brain volume of humans appears to have been shrinking in $\mathrm{H}$. sapiens, when compared to earlier homo species (but this could also be a sign of optimising the brain's efficiency). Air/water pollution and mental health problems are reducing fertility. But are these evolutionary mechanisms rapid enough to change our brain and nature in time for a non-catastrophic transition? Probably not, alas.

Although I have some disagreements with the author, I agree that "Despite the development of psychological, moral, behavioural ('self-domestication'), pharmacological and technological solutions, we are knowingly and consciously pursuing our unsustainable development that is rapidly destroying the resources upon which we critically depend. However, globally engaging in the actions required to change our current trajectory and achieve long-term sustainability appears contrary to human nature."

Unless intelligence is deployed more adaptively, the world and the creatures in it are at serious 
risk (Sternberg, 2021). The question is whether we want to create a future for our progeny over many generations, or rather for many generations of viruses, bacteria, and, inevitably, the everpresent cockroaches.

Unfortunately, rather than changing our ways to favour our progeny, we seemingly prefer not to change and rather wait for a deus ex machina-with a machina being created by the same technology, and a deus with the same nature, that put us (and the rest of the planet) in this dire situation. A rational person would bet on the cockroach.

Competing Interests: there are no competing interests to declare.

Reviewer Report 14 October 2020

https://doi.org/10.5256/f1000research.28862.r72866

(c) 2020 Iriki A et al. This is an open access peer review report distributed under the terms of the Creative Commons Attribution License, which permits unrestricted use, distribution, and reproduction in any medium, provided the original work is properly cited.

\section{Rafael Bretas Vieira}

Laboratory for Symbolic Cognitive Development, RIKEN Center for Biosystems Dynamics Research, Kobe, Japan

\section{Atsushi Iriki}

Laboratory for Symbolic Cognitive Development, RIKEN Center for Biosystems Dynamics Research, Kobe, Japan

The author's revision of the manuscript satisfactorily addresses all concerns raised. The responses open to the reader, together with the respective references added, provide a clear justification for the statements made and an insightful view on the process of thought that led to each statement.

Is the topic of the opinion article discussed accurately in the context of the current literature?

Partly

Are all factual statements correct and adequately supported by citations? Partly

Are arguments sufficiently supported by evidence from the published literature? Partly

Are the conclusions drawn balanced and justified on the basis of the presented arguments? Partly

Competing Interests: No competing interests were disclosed. 
Reviewer Expertise: Spatial navigation, neuro-electrophysiology, behavioral psychology, consciousness, bodily self-awareness.

We confirm that we have read this submission and believe that we have an appropriate level of expertise to confirm that it is of an acceptable scientific standard.

\section{Version 1}

Reviewer Report 03 July 2020

https://doi.org/10.5256/f1000research.24305.r65187

(C) 2020 Iriki A et al. This is an open access peer review report distributed under the terms of the Creative Commons Attribution License, which permits unrestricted use, distribution, and reproduction in any medium, provided the original work is properly cited.

\section{Rafael Bretas Vieira}

Laboratory for Symbolic Cognitive Development, RIKEN Center for Biosystems Dynamics Research, Kobe, Japan

\section{Atsushi Iriki}

Laboratory for Symbolic Cognitive Development, RIKEN Center for Biosystems Dynamics Research, Kobe, Japan

The manuscript discusses the uniqueness of human intelligence (HI) despite its apparent evolutionary advantages. Although the theme has been tirelessly revisited by many authors, a new theory is offered, that higher intelligence is disadvantageous and kept from developing through negative feedback. The author briefly goes through the main molecular and ecological arguments for the appearance and advantages of high intelligence, showing that those are not especially uncommon or slow in evolutionary history. Therefore, none could fully justify the evolution of HI, suggesting it to be generally an unfavorable trait.

The theory is well constructed and the references support the hypothesis. Despite that, there are a few points in the manuscript that warrant attention:

\section{Page 3 - "Brain size, structure, and complexity"}

The author affirms that "In terms of genetic modifications, the development of the human brain therefore appears to be based on extending already existing features through gradual and common mechanisms, rather than being the result of a developmental quantum leap" (page 3, para 5, line 33). The example given a few lines before, of Pax6, as well as other well known genes, such as the human-specific ARHGAP11B, despite being relatively small changes, result in significant leaps in brain development. The later example of octopuses also seems to indicate a sudden change, from the moment molluscs lost their shells, which still supports the paragraph conclusion that the genetic mechanisms that allow intelligence are available to other species.

\section{Page 5 - "Language and intelligence"}


In general, this session is not clear about language being a requirement for the development of $\mathrm{HI}$, a mere consequence of it, or something in between, with some contradictions. For example "It is therefore not the capacity for an articulate vocalization, but only a predisposition for it, that is essential to the evolution of HI" (page 5, para 5, line 11) and "current evidence suggests that the evolution of a HI-supporting language is not a feature strictly limited to humans or the human brain anatomy or speech production" (page 5, para 7, line 6). The conclusion is especially confusing when declaring "HI-supporting language" while the manuscript appears to state that language is not a prerequisite for $\mathrm{HI}$.

About the passage:

"Let us now consider language syntax and acquisition with respect to human uniqueness. It has indeed been proposed that such properties of the human language are neither specific to language nor to humans $(47,48)$ " (page 5 , para 6 , line 1$)$. The references cited $(47,48)$ indicate that there may be a human-only syntax, either through universal grammar or simply an advanced form of syntax allowed by the human FLB.

\section{Page 7 - "Conclusion and outlook"}

Despite mentioning the possible negative feedback from molecular complexity, I couldn't find any examination of it in the main text. For reference: "the main barrier towards $\mathrm{HI}$ is not only the development of the required physical assets, but also that negative feedback from social, behavioural and molecular complexity, as well as negative environmental feedback make the development of HI increasingly unfavourable" (page 7, para 4, line 11).

I wonder if there is a link between $\mathrm{HI}$ and sexual selection. Although intelligence as a simple fitness indicator would be equally accessible to other animals as well, cultural and behavioral products could also have influenced mating preferences.

Finally, the text mentions the possible negative feedback of niche construction: page 7, "there might be a different type of negative feedback loop intrinsic to HI-HI might simply allow a species to become so successful in exploiting food resources that these resources become exhausted" (page 7, para 3, line 1) and again on the conclusion "we are knowingly and consciously pursuing our unsustainable development that is rapidly destroying the resources upon which we critically depend" (page 7, para 6, line 6). Despite that, HI also generates powerful positive feedback with niche construction, in which the environmental changes produced by $\mathrm{HI}$ favor $\mathrm{HI}$ itself.

\section{Is the topic of the opinion article discussed accurately in the context of the current literature?}

Yes

\section{Are all factual statements correct and adequately supported by citations?}

Yes

Are arguments sufficiently supported by evidence from the published literature? Partly

Are the conclusions drawn balanced and justified on the basis of the presented arguments? Yes

Competing Interests: No competing interests were disclosed. 
Reviewer Expertise: Spatial navigation, neuro-electrophysiology, behavioral psychology, consciousness, bodily self-awareness.

We confirm that we have read this submission and believe that we have an appropriate level of expertise to confirm that it is of an acceptable scientific standard, however we have significant reservations, as outlined above.

Author Response 14 Aug 2020

Stefan Arold, King Abdullah University of Science and Technology, Thuwal, Saudi Arabia

I thank Dr. Atsushi and Dr. Vieira for their time and efforts to critically evaluate my manuscript, and for their very constructive feedback. In the following I provide a point-bypoint reply to their comments, outlining also the changes I have made to the manuscript. I hope that my explanations (given below, which are accessible to readers) and manuscript changes respond to the reviewer's comments in a satisfactory manner. Should issues remain, I'd be happy to further discuss and integrate these.

\section{Reply to comment on Page 3 -“ Brain size, structure and complexity"}

The reviewers refer to my statement that "In terms of genetic modifications, the development of the human brain, therefore, appears to be based on extending already existing features through gradual and common mechanisms, rather than being the result of a developmental quantum leap" (page 3, para 5, line 33). They note that the "relatively small changes [in genes] result in significant leaps in brain development."

I thank the reviewers for this comment that identifies a poor formulation in my essay. Indeed, I argue (in agreement with the reviewers) that the apparently big anatomical and cognitive changes were caused by only relatively small genetic changes. Consequently, I have corrected the wording into: "rather than being the result of a genetic quantum leap."

\section{Reply to comment on Page 5 - "Language and intelligence"}

The reviewers note that "this session is not clear about language being a requirement for the development of HI, a mere consequence of it, or something in between, with some contradictions ", and they give specific examples for this contradiction.

My position is that 'full-blown' HI needs a powerful communication system; however, Australopithecines and very early homo forms did certainly not have the language necessary to produce modern legislation, Shakespearean theatre or comprehensive gene ontologies. Hence, although a powerful communication system is a requirement for $\mathrm{HI}$, it can (and probably will) be developed while a species develops HI. I agree that some of my formulations lacked precision, and I have now amended the text to enhance the clarity of this message:

"we then have to ask whether the development of HI-supporting language would be possible for other species".

"It was therefore not the pre-existence of an articulate vocalisation, but only a physiological potential for it, that was sufficient for allowing the evolution of HI in humans".

"Thus, current evidence suggests that the capacity for developing a HI-supporting system of communication is not a feature strictly limited to humans or the human brain anatomy or speech production." 
I thank Dr. Atsushi and Dr. Vieira for pointing out the mismatch between references and statement in the passage "let us now consider language syntax [...]47,48". Indeed, these references should not have been mentioned at this position, because the references for this statement follow in the ensuing discussion (references 50-57). Therefore, in the revised version, I have deleted the references 47,48 at this position (they are still used in the preceding passage) and put a colon instead of the full-stop for additional clarity.

\section{Reply to comment on Page 7 - "Conclusion and outlook"}

The reviewers rightly ask: "Despite mentioning the possible negative feedback from molecular complexity, I couldn't find any examination of it in the main text.". Indeed, in the initial version, 'molecular complexity' refers to the extension of protein-level amino-acid repeats that are linked to both, increased cognition, but also increased psychopathology. I gave the protein huntingtin as an example. However, I agree that such repeat extensions (which are frequently linked to cognition and neurological pathologies) are not adequately described as 'molecular complexity'. Moreover, the genetics of mental illness are only emerging very slowly, with different studies often reaching different conclusions (for a summary, please see M. Marshall, Nature 581, 19-21 (2020) doi: 10.1038/d41586-020-00922-8). Hence, it is also premature for general correlations between complexity and psychopathology on a molecular level.

However, over the last decade, a good consensus has been reached that mental disorders can involve altered connectivity in our highly complex brains (e.g. Fornito and Harrison, Front. Psychiatry, 27 July 2012 https://doi.org/10.3389/fpsyt.2012.00072). My manuscript already refers to it in "HI as an intrinsically unfavourable trait", p7, in the two sentences following the mentioning of huntingtin ("[...]the genes regulating synaptogenesis and neuronal circuit formation have been associated with an increased risk of mental illnesses. [...] brain networks involved in HI-required cognitive skills, such as language and complex social behaviour, have less compensatory mechanisms, and are hence less robust, than more ancient biological functions". Hence, to respond to the reviewers' comment, I have changed 'molecular complexity' into 'neuroanatomical complexity' in this sentence.

The reviewers also 'wonder if there is a link between HI and sexual selection'. This is an interesting suggestion, and my thoughts on it are as follows: Interspecies variations in $\mathrm{HI}$ would not change the outside appearance and appeal of one individual with respect to a rival. However, above-average $\mathrm{HI}$ might indirectly influence mating preferences, for example through resulting in a higher in-group social status, better food sources (and hence physical fitness), and, at a more advanced stage, more attractive cultural/ornamental items. However, given the wide-spread occurrence of sexual selection across animal species, I don't see how sexual selection would uniquely favour $\mathrm{HI}$ in homo, but not in any other species. Hence, while sexual selection might have an influence, this influence would not be specific enough to humans to justify that HI has only emerged in our lineage.

In their final comment, the reviewers refer to my discussion on the possible negative feedback of niche construction. In particular, they refer to my discussion of data showing the unsustainable nature of $\mathrm{HI}$ in its current 'implementation' in modern humans, ultimately making $\mathrm{HI}$ a maladaptive feature ["HI might [...] allow a species to become so successful in 
exploiting food resources that these resources become exhausted"; and "we are knowingly and consciously pursuing our unsustainable development that is rapidly destroying the resources upon which we critically depend"]. The reviewers suggest that "despite that, HI also generates powerful positive feedback with niche construction, in which the environmental changes produced by HI favour HI itself."

In response, I argue that both statements do not contradict each other. Rather, they consider different effects resulting in this feedback mechanism.

Niche construction theory states that acquired features that allow a species to favourably transform its environment can be selected for during evolution. If a species can use its intelligence to 'consciously' and favourably alter its environment, then this would certainly result in positive feedback for the development of $\mathrm{HI}$. The dam-building beaver is an obvious example for 'intelligent' niche construction (as opposed to, say, cyanobacteria or earthworms). Hence, I agree with the reviewers and existing literature (e.g. doi:10.1098/rstb.2010.0306) that 'conscient' niche construction can boost the development of HI. However, two aspects are important in the context of my essay:

Firstly, nothing indicates that the positive feedback between $\mathrm{HI}$ and the development of 'conscient' niche construction is limited to humans. Hence, niche construction would not explain the main focus of my manuscript, namely the uniqueness of $\mathrm{HI}$ in humans. To take into account the reviewer's comments, and to directly clarify this point, I have added the general aspect of niche construction in my revised manuscript (see: Lack of suitable environment?: "Additionally, if the competitive advantage and driving force of HI development lies in overcoming dependence of the environment ${ }^{14}$, or enables favourable niche construction, then this advantage would profit many species, and hence is not a limiting factor. ").

Secondly, while niche construction may support the development of increased cognition, this synergy will become overall maladaptive if the changes to the environment deplete the food resources. As a non-human example, I have mentioned the study on island populations of long-tailed macaques. Obviously, through $\mathrm{HI}$, humans were able to consciously alter their environment more than any other animal (cyanobacteria might have altered our planet even more than humans, but not 'consciously'). However, as I note in my manuscript, available studies overwhelmingly conclude that these HI-enabled environmental changes are unsustainable because they are "rapidly destroying the resources upon which we critically depend". Hence, the environment-transforming capacity of HI is now critically endangering the survival of our species-and this is the 'increasingly negative side effects' of our HI that I refer to in the 'Conclusion and Outlook' section.

Competing Interests: No competing interests were disclosed.

\section{Comments on this article}

\section{Version 3}


Stefan Arold, King Abdullah University of Science and Technology, Thuwal, Saudi Arabia

I just added an extended speculation on how HI could occur in humans despite intrinsic negative feedback here: https://www.researchgate.net/publication/357332418_Intrinsic-Negative-

Feedback_Extended_discussion_2021pdf

I also note that such intrinsic negative feedback might be an additional explanation for the Fermi paradox.

Competing Interests: I declare no competing interests

The benefits of publishing with F1000Research:

- Your article is published within days, with no editorial bias

- You can publish traditional articles, null/negative results, case reports, data notes and more

- The peer review process is transparent and collaborative

- Your article is indexed in PubMed after passing peer review

- Dedicated customer support at every stage

For pre-submission enquiries, contact research@f1000.com 